\title{
Effect of Silica Fume on Mechanical and Durability Properties of Recycled Coarse Aggregate Concrete
}

\author{
Premkumar R, Ramesh Babu Chokkalingam, M Shanmugasundaram, S.Rajesh
}

\begin{abstract}
Reusing concrete is the best choice to diminish the eagerness on mind blowing standard assets and to oblige the total of waste which is engineered in landfills. Reused concrete has been regularly used as an unbound material as a touch of dams, bases, and sub-bases. RAC has in like way been utilized as a piece of the improvement of asphalts and wastes yet in less case as the examination in this field is not the most outrageous utmost of $R A C$ has not yet been investigated. In this investigation the reused total was utilized as supplanting with $20 \%, 40 \%, 60 \%$ and $80 \%$ by substitution of typical aggregate. Standard Ordinary Portland cement was supplanted with $10 \%$ of mineral admixture silica fume. Tests were coordinated to choose the mechanical properties and durability properties such us rapid chloride penetrability test and water sorptivity test. The results show that increasing the recycle aggregate percentage above $40 \%$ with natural aggregate, small modifications to the mix design may be adopted to secure that comparable property to natural aggregate concrete is attained.
\end{abstract}

Keywords: Durability, Mechanical, Recycled Aggregate, Silica fume.

\section{INTRODUCTION}

One of the certifiable difficulties of our present society is the affirmation of condition. A bit of the key parts in this thankfulness are the decreasing of the usage of essentialness and typical unrefined materials and use of waste materials. The use of reused aggregates from advancement and destruction misuses is exhibiting approaching application being developed as other choice to vital sums. It moderates ordinary resources and reduces the space required for the landfill transfer. The vast majority of the waste materials created by crushing structures are arranged by dumping them as area fill or for recovering area. Including the expense of transportation, that makes the transfer a noteworthy issue. Thus reuse of decimation waste gives off an impression of being a powerful arrangement and the most fitting and huge

Revised Manuscript Received on December 05, 2019.

* Correspondence Author

Premkumar R*, School of Environmental and Construction Technology, Department of Civil Engineering, Kalasalingam Academy of Research and Education, Krishnan Koil, Tamil Nadu, India.Email: prem.ce@gmail.com

Ramesh Babu Chokkalingam, School of Environmental and Construction Technology, Department of Civil Engineering, Kalasalingam Academy of Research and Education, Krishnan Koil, Tamil Nadu, India.

M Shanmugasundaram, School of Mechanical and Building Sciences, Vellore Institute of Technology, Chennai, Tamil Nadu, India

S.Rajesh, School of Environmental and Construction Technology, Department of Civil Engineering, Kalasalingam Academy of Research and Education, Krishnan Koil, Tamil Nadu, India. scale use would be to utilize it as totals to deliver concrete for new development. The massive measures of demolished concrete are open at various advancement regions, which are in the blink of an eye speaking to a noteworthy issue of move in urban zones. This can without a lot of a stretch be reused as total and utilized as a bit of bond. Inventive work practices have been taken up everywhere all through the world for displaying its credibility, cash related reasonableness and cost plausibility. Togay Ozbakkaloglu et.al [1] revelations on this examination recommend that with lower reused complete total (i.e., up to $25 \%$ ) it is possible to make RACs with mechanical and sturdiness properties that resemble those of common aggregate having the proportionate compressive quality. The development in the versatile modulus is attributed to the lower ITZ increment the level of reused aggregate, and the decrease in the flexural properties can be explained by the lower mortar quality containing increment coarse aggregate achieved by their higher incredible water binder proportion. B. Gonza' lez-Fonteboan [2] investigation of study recycled coarse aggregate concrete was made with $8 \%$ of silica fume concrete. [3] The mechanical properties of reused cement contained with silica fume were additionally in like manner like that of typical cement with mineral admixture. In any case, in all type of replacement mixes following 28 days the recycled aggregate showed more prominent compressive strength than the normal concrete. $\mathrm{O}$ zgur C, akır [4] Water absorption estimations of cements having the reused aggregate with mineral admixture were diminished altogether particularly at later ages. Nwzad Abduljabar Abdulla [5], [6] studied impact of size of the reused totals on the quality and workability of the solid is talked about in this paper. In this examination, the solid creation with fractional supplanting of the normal total by reused total is concentrated.

\section{EXPERIMENTAL PROGRAM}

\section{A. Binding Material}

In this study ordinary Portland cement 43 grade and silica fume were used preparation of specimens. Specific gravity and consistency of cement was found 3.279 and $30.5 \%$ and initial setting time was 30minutes. Silica fume has one of the good concrete admixtures of normal cement concrete. In this study was used $10 \%$ replacement of silica fume with ordinary Portland cement for increase the compressive strength of concrete.

\section{B. Fine Aggregate}


Locally available sand free from silt, organic matter and passing through $4.75 \mathrm{~mm}$ sieve confirming to zone II as per IS 383 was used as fine aggregate. The specific gravity of sand was used 2.492 .

\section{Coarse Aggregate}

The decimated waste cement required for the present study was acquired from the building annihilation exercises which were experiencing close to our area. The devastated cement was smashed physically to acquire the totals with joined mortar in them. These totals were washed altogether to expel the stuck mortar to most extreme conceivable degree before leading primer tests. At that point these reused totals were dried and utilized as coarse totals as a part of new concrete. Recycled aggregates were obtained the following procedures. The natural coarse aggregate of maximum size $12.5 \mathrm{~mm}$ passing and retained on $4.75 \mathrm{~mm}$ sieve is used and the specific gravity used is 2.657 . The recycled coarse aggregate size of maximum size $12.5 \mathrm{~mm}$ passing and retained on $4.75 \mathrm{~mm}$ sieve is used and the specific gravity is 2.469. The physical properties comparison of natural coarse aggregate with Recycle aggregate in table I.

Table- I: Physical Properties Of Natural Aggregate And Recycle Aggregate

\begin{tabular}{|c|l|l|l|}
\hline S.No & \multicolumn{1}{|c|}{ Property } & \multicolumn{1}{|c|}{$\begin{array}{c}\text { Natural } \\
\text { Aggregate }\end{array}$} & \multicolumn{1}{|c|}{$\begin{array}{c}\text { Recycle } \\
\text { Aggregate }\end{array}$} \\
\hline 1 & Specific Gravity & 2.657 & 2.469 \\
\hline 2 & Water Absorption & $0.311 \%$ & $2.24 \%$ \\
\hline 3 & Fineness Modulus & 6.25 & 5.45 \\
\hline 4 & Bulk Density & $1.404 \mathrm{~kg} / \mathrm{l}$ & $1.31 \mathrm{~kg} / \mathrm{l}$ \\
\hline 5 & Crushing Value & $28 \%$ & $28 \%$ \\
\hline 6 & Impact Value & $21 \%$ & $30 \%$ \\
\hline
\end{tabular}

\section{CONCRETE MIX PROPORTIONS}

In this investigation production of high strength concrete M60 using recycled aggregates is attempted. Many researchers have been carried out till now on recycled aggregate concrete for normal strength concrete and also they have been successful in replacing natural aggregate even up to $100 \%$ by recycled aggregates to produce normal strength concrete. So the following huge advances are attempt and use them in high strength concrete. Further the ordinary strength concrete is utilized in all the general development works like structures. Furthermore, for this less strength is required as analyzed other sort of development works like for example buildings. And for this very less concrete is required as compared other type of construction works like for instance bridges. Also further only a small quantity of natural aggregates will be replaced by recycled aggregates. Hence the usage of demolished concrete recycled aggregates in new concrete is very less and hence only a small quantity of the demolished wastes generated will be used and the remaining will still be left as waste. Hence we can use larger quantities of demolished wastes reducing the waste generation for heavy structures. Thus, the mix proportions for M60 grade concrete different percentage replacement by RCA are given in the table II. Once the concrete was poured in moulds, they were compacted thoroughly by placing on table vibrator. After De-moulding the specimens were kept for curing in the curing tank. In this study mechanical properties of the cube specimens for testing compression test, beam specimens for flexure test and cylindrical specimens for split tensile strength have been cast and kept for curing for a period of 28 days and then tested for their respective strengths. Durability properties[7] to be specific water sorptivity and chloride particle infiltration of above high strength concrete containing recycled aggregate concrete additionally contemplated and contrasted and that of normal aggregate concrete so as to assess the impacts of different recycled aggregate concrete on the solidness of high strength concrete.

Table- II: Mix Proportion for Normal Ordinary Portland cement Concrete

\begin{tabular}{|c|c|c|c|c|c|c|}
\hline Mix Id & $\begin{array}{c}\text { Cement } \\
\mathbf{k g} / \mathbf{m}^{\mathbf{3}}\end{array}$ & $\begin{array}{c}\text { Silica } \\
\mathbf{f u m e} \\
\mathbf{k g} / \mathbf{m}^{\mathbf{3}}\end{array}$ & $\begin{array}{c}\text { Sand } \\
\mathbf{k g} / \mathbf{m}^{\mathbf{3}}\end{array}$ & $\begin{array}{c}\mathbf{N C A} \\
\mathbf{k g} / \mathbf{m}^{\mathbf{3}}\end{array}$ & $\begin{array}{c}\mathbf{R C A} \\
\mathbf{k g} / \mathbf{m}^{\mathbf{3}}\end{array}$ & $\begin{array}{c}\mathbf{W a t e r} \\
\mathbf{k g} / \mathbf{m}^{\mathbf{3}}\end{array}$ \\
\hline RCA0\% & 360 & 40 & 762 & 1000 & 0 & 160 \\
\hline RCA20\% & 360 & 40 & 751 & 800 & 200 & 160 \\
\hline RCA40\% & 360 & 40 & 736 & 600 & 400 & 160 \\
\hline RCA60\% & 360 & 40 & 722 & 400 & 600 & 160 \\
\hline RCA80\% & 360 & 40 & 711 & 200 & 800 & 160 \\
\hline
\end{tabular}

\section{RESULT AND DISCUSSION}

\section{A. Compressive Strength}

The compressive strength of 7, 14 and 28 days was distinctive rate substitution of coarse aggregate in high strength concrete as appeared in figure 1. All the test outcomes were obtained from the average strength of three $150 \mathrm{~mm} \times 150 \mathrm{~mm} \times 150 \mathrm{~mm}$ cube specimens of each mix proportion. After 28 days RCA0\% had a compressive strength $69.3 \mathrm{~N} / \mathrm{mm}^{2}$; RCA20\%, 40\%, 60\% and $80 \%$ concrete mixes contained recycle aggregate had respective compressive strength of $68 \mathrm{~N} / \mathrm{mm}^{2}, 59 \mathrm{~N} / \mathrm{mm}^{2}, 52 \mathrm{~N} / \mathrm{mm}^{2}$ and $49 \mathrm{~N} / \mathrm{mm}^{2}$. When looking the compressive strength of specimens was decrease with a raise of the substitution level of reuse coarse aggregate. However the utilization of silica fume was $10 \%$ somewhat substitution of binding material likewise caused a decrease in the compressive strength. It was seen that in all kind of concrete mixes, the compressive strength was above the design value of strength with the exception of RCA60\% and RCA $80 \% 60$ and RCA80\% recycle aggregate supplanted concrete. When the replaced recycle aggregate was added by $20 \%$, its compressive strength declined on $13 \%$ and $18 \%$ for RCA60\% and RCA80\% respectively.

\section{B. Split tensile Strength}

Figure. 2 shows the 28 days split tensile strength for recycle coarse aggregate concrete was obtained from the average tensile strength of three $150 \times 300 \mathrm{~mm}$ cylinder specimens of each mix proportion. The outcome demonstrates that splitting tensile strength of the concrete mix proportion was 
diminished with an increased the amount of recycled aggregate in the concrete mix. Usually adding of silica fume is increase the pozzolanic action of high strength concrete. Its lead us to enhance the every mechanical property of high strength concrete. But this investigation was shows including of mineral admixtures additionally not improve the mechanical properties recycle aggregate concrete. The split tensile test exhibits that ordinary concrete has elasticity around $8-14 \%$ of the compressive strength.

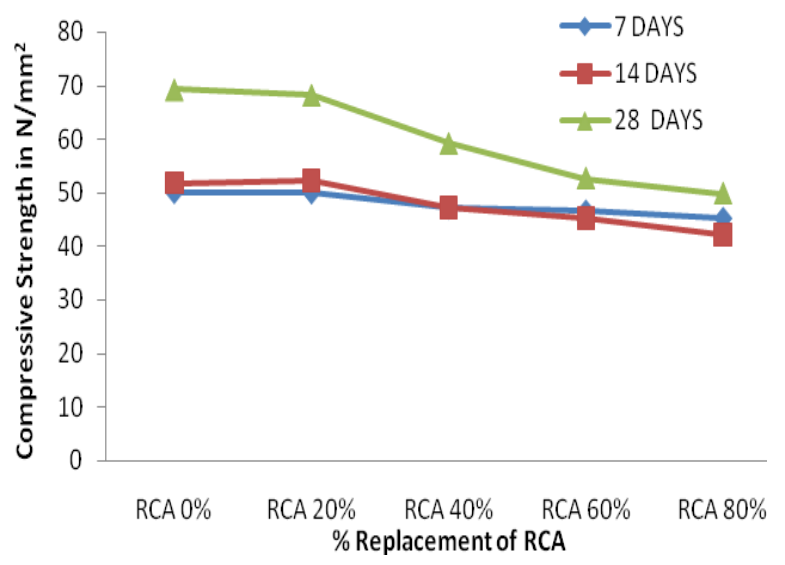

Fig. 1.Compressive Strength of Recycled Coarse Aggregate

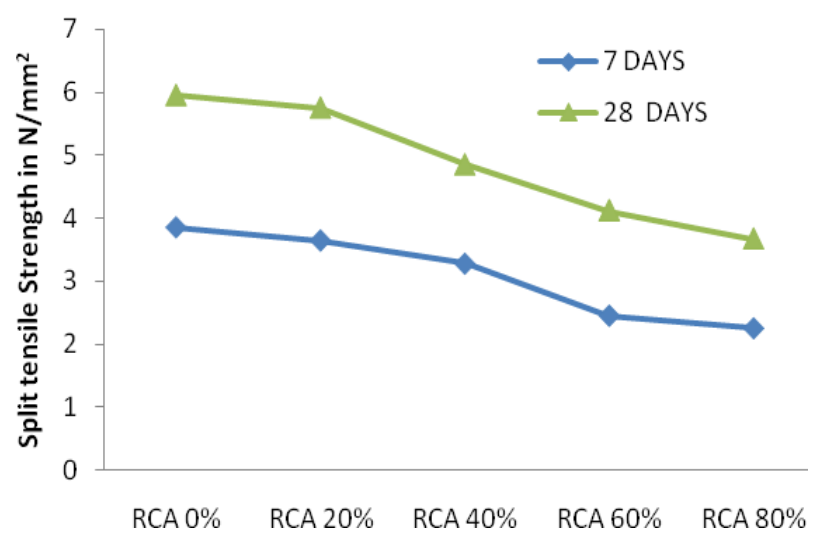

Fig. 2. Split Tensile Strength of Recycled Coarse Aggregate

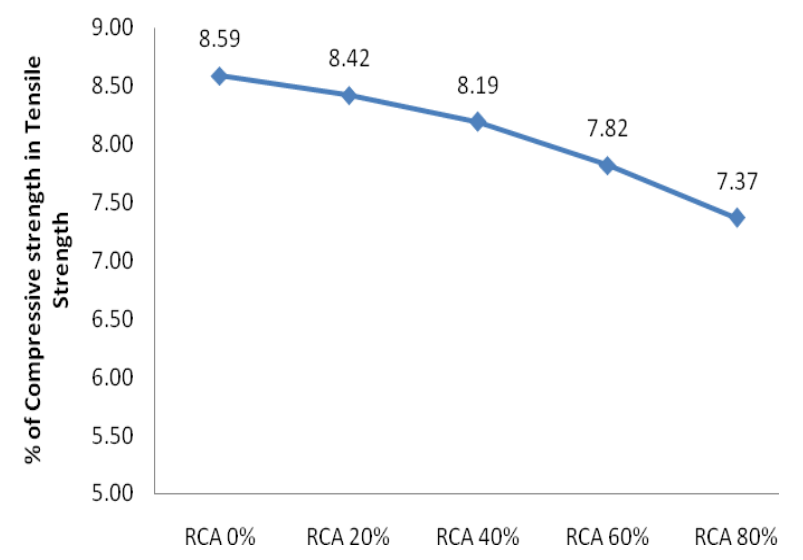

Fig. 3. Relation between Percentage of Split Tensile Strength to Compressive Strength
Figure 3 shows the percentage of tensile strength with respect to compressive strength of corresponding recycle aggregate concrete was within the limit of $8-14 \%$ up to $40 \%$ replacement of coarse aggregate. After substitution of more than $40 \%$ reused aggregate was lower than $8 \%$ of the level of compressive strength. The nearest split tensile strength was attained in $40 \%$ replacement of recycled aggregate with natural aggregate.

\section{Flexural Strength}

Flexural Strength test outcomes were obtained from the average strength of three $100 \times 100 \times 500 \mathrm{~mm}$ prism specimens of each mix proportion using two point load bending test. Figure. 4 shows the 28 days Flexural strength for natural aggregate concrete $0 \%$ replacement of recycled aggregate was maximum compare with other mix proportion with $10 \%$ silica fume. This discernment can be attributed to the diminishing in the quality of the all out mortar interfacial transition zone with a development in the proportion of reused aggregate in the specimen, realizing a lower mechanical strength under twisting nature.

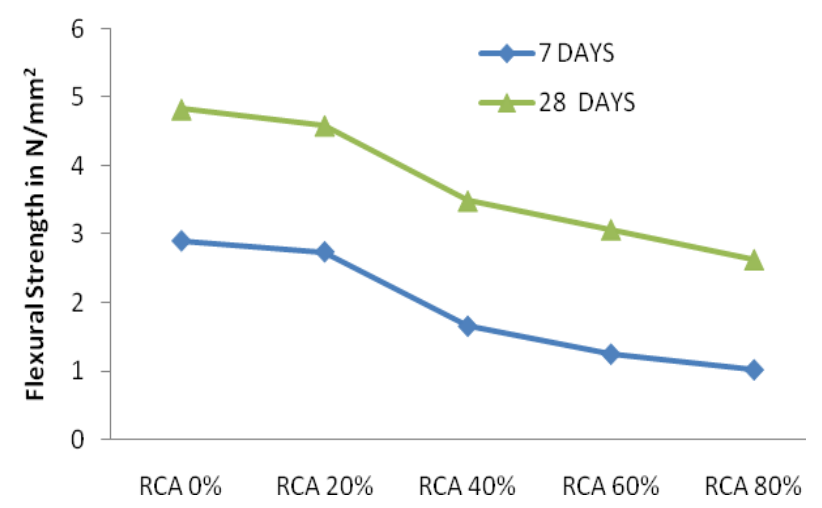

Fig. 4. Flexural Strength of Recycled Coarse Aggregate

\section{Rapid Chloride Permeability Test}

RCPT test According to ASTM C1202 test, $50 \mathrm{~mm}$ thick, $100 \mathrm{~mm}$ thick estimation solid example is presented to associated DC voltage of $60 \mathrm{~V}$ for 6 hours. In one holder $3.0 \%$ $\mathrm{NaCl}$ game plan and in the other compartment $0.3 \mathrm{M} \mathrm{NaOH}$ courses of action as appeared in figure 5. [8]

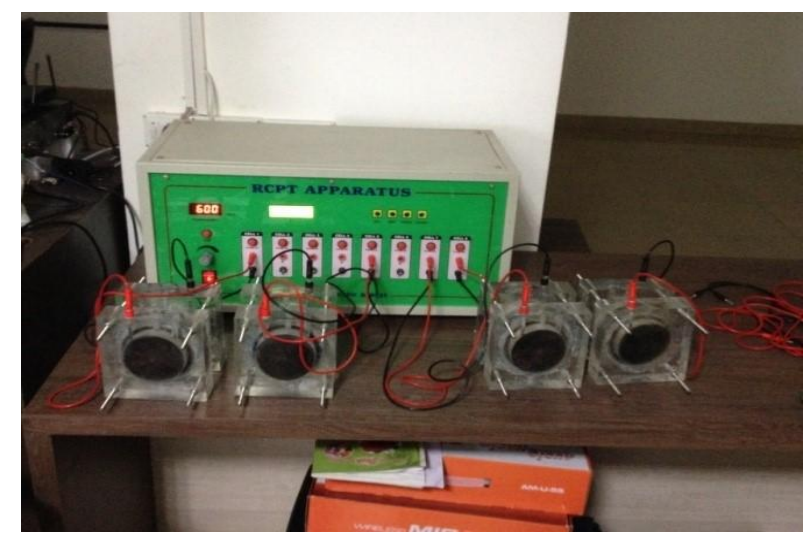

Fig. 5. Rapid Chloride Permeabitity test setup

Table III shows that results of this experiment In this experiment 
the chloride passes through the concrete sample which taken at the curing periods 28 days, this passing chloride shows that the permeability of the concrete, the charge passed through coloumbs values are taken from the equipment display, and this values are compared with the standard values which are mentioned by ASTM C1202..

Table- III: Rapid Chloride permeability

\begin{tabular}{|c|l|l|l|}
\hline S.No & \multicolumn{1}{|c|}{ Mix Id } & $\begin{array}{c}\text { Charge Pass } \\
\text { In Coloumbs } \\
(\mathbf{C})\end{array}$ & As Per ASTM \\
\hline 1 & RCA 0\% & 2502 & Moderate \\
\hline 2 & RCA20\% & 2805 & Moderate \\
\hline 3 & RCA40\% & 2315 & Moderate \\
\hline 4 & RCA60\% & 2010 & Moderate \\
\hline 5 & RCA80\% & 1815 & Low \\
\hline
\end{tabular}

\section{E. Sorptivity}

The sorptivity can be banished by the appraisal of the hairlike ascent degree of consistency on reasonably homogeneous material. Water was utilized of the test fluid. The chambers in the wake of hurling were absorbed water for 28 days moderating. The model measure $100 \mathrm{~mm}$ dia $x 50 \mathrm{~mm}$ stature in the wake of drying in holder at temperature of $100+$ $10{ }^{\circ} \mathrm{C}$ were choked with water level not more than $5 \mathrm{~mm}$ above as appeared in fig.6. The test result table IV can be seen that the conscious water sorptivity, water maintenance and volume of permeable voids of run of the mill concrete containing reused aggregate are lower than trademark all out bond containing a comparative whole and sort of reused coarse aggregate[9]. This demonstrates the pore structures [10], their transport and preeminent volumes of reused aggregate concrete are fundamentally improved than the common coarse aggregate concrete.

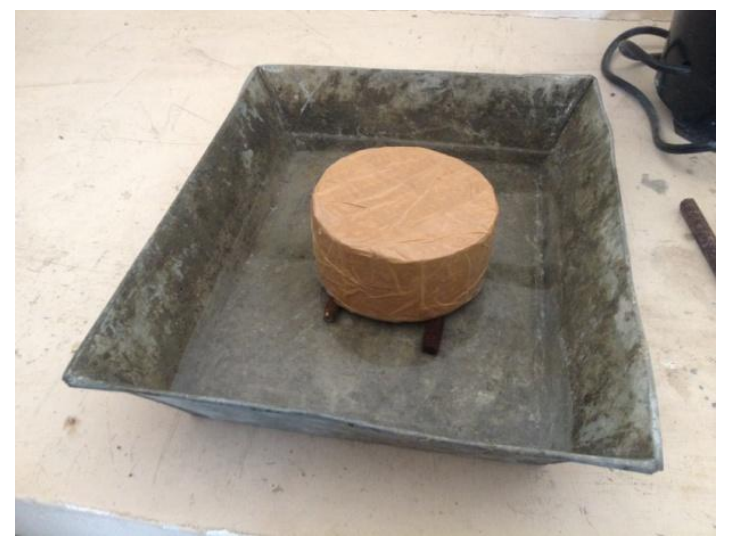

Fig. 6. Sorptivity test Arrangement

Table- IV: Sorptivity test

\begin{tabular}{|c|c|c|c|}
\hline S.No & Mix Id & $\begin{array}{c}\text { Sorptivity } \mathbf{~} \\
\mathbf{1 0} \text {-6 } \mathbf{~ m m} / \\
\mathbf{m i n} \mathbf{. 5}\end{array}$ & $\begin{array}{c}\text { Rate of } \\
\text { Absorption I } \\
\text { mm }\end{array}$ \\
\hline 1 & RCA0\% & 4.50 & 101.62 \\
\hline 2 & RCA20\% & 5.36 & 111.23 \\
\hline 3 & RCA40\% & 6.28 & 125.60 \\
\hline 4 & RCA60\% & 6.72 & 131.49 \\
\hline 5 & RCA80\% & 7.36 & 143.56 \\
\hline
\end{tabular}

\section{CONCLUSION}

The accompanying end can be suffocating dependent on the exploratory investigation on the impact of reused coarse aggregate in high strength concrete with silica fume.

- Concrete mix proportion making with recycled and natural aggregate add in $10 \%$ silica fume go through decline high strength concrete.[11]

- When the replaced recycle aggregate was added greater than $40 \%$, its compressive strength declined on $13 \%$ and $18 \%$ for RCA60\% and RCA $80 \%$ respectively.

- However mechanical properties of tensile strength and flexural strength of concrete restraining was reduction the mineral admixture of high strength concrete due to mortal action. [12].

- Rapid chloride permeability test of different concrete mix proportion of recycled concrete the charge passed through coloumbs values diminished as the recycled aggregate substance increased.

- The protection from chloride molecule passageway lessened as the reused concrete substance extended. In any case, the opposition was improved by joining silica fume remains in the concrete mixers.

- The durability properties of recycled high strength concrete such as RCPT and sorpitivity are also unfavorably exaggerated due to adding of recycled concrete. Anyway these properties are lower than ordinary aggregate concrete containing same sum and diverse blend extent of recycled concrete.

\section{ACKNOWLEDGMENT}

The authors would like to place their gratitude to the Kalasalingam Academy of Research and Education students G.Abhishek, T.Sai Dharanish and Raj Kumar Reddy of B.Tech. Civil Engineering for their help in casting and testing of the recycled aggregate concrete.

\section{REFERENCES}

1. Ozbakkaloglu, T.; Gholampour, A.; Xie, T.Y. "Mechanical and durability properties of recycled aggregate concrete: Effect of recycled aggregate size and content on the behaviour". J. Mater. Civ. Eng. vol 30, pp. 04017275, 2017.

2. B. Gonza' lez-Fonteboa , F. Martı'nez-Abella, "Concretes with aggregates from demolition waste and silica fume Materials and mechanical properties," Building and Environment, vol 43, pp. 429-437, 2008.

3. Isaia, G. C., Gastaldini, A. L. G., and Moraes, R."Physical and pozzolanic action of mineral additions on the mechanical strength of high-performance concrete." Cem. Concr. Vol. 25, pp. 69-76, 2003

4. O "zgür C, akır, O" mer O " zkan Sofyanl," Influence of silica fume on mechanical and physical properties of recycled aggregate concrete," Housing and Building National Research Center, vol 11, pp. 157-166, 2014

5. Nwzad Abduljabar Abdulla1," Effect of Recycled Coarse Aggregate Type on Concrete". J. Mater. Civ. Eng. vol. 27(10), pp. 04014273, 2015.

6. Katkhuda, H.; Shatarat, N. "Shear behavior of reinforced concrete beams using treated recycled concrete aggregate.", Constr. Build. Mater., vol 125, pp. 63-71, 2016

7. P. Saravana Kumar and G Dhinakaran, "Effect of Admixed Recycled Aggregate Concrete on Properties of Fresh and Hardened

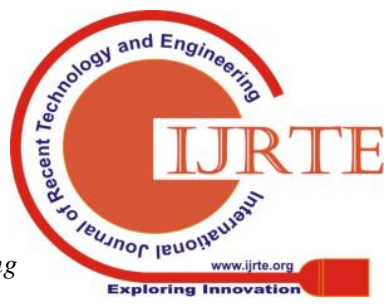


Concrete", Journal of Materials in Civil Engineering, vol. 24, pp. 494-498, 2012

8. R Premkumar, Ramesh Babu Chokkalingam and $\mathrm{M}$ Shanmugasundaram, "Durability Performance of Fly Ash and Steatite Powder Based Geopolymer Concrete", IOP Conference Series: Materials Science and Engineering, vol. 561, 012055, 2019, Available from: https://doi.org/10.1088/1757-899X/561/1/012055

9. M Thomas, C.; Setién, J.; Polanco, J.A.; Alaejos, P.; de Juan, M.S. “ Durability of recycled aggregate concrete".Constr. Build. Mater., vol 40, pp. 1054-1065, 2013.

10. Shaikh, F.U.A., Nguyen, H.L., "Properties of concrete containing recycled construction and demolition wastes as coarse aggregates,"J.Sust. Cem. Mater., vol 2 (3-4), pp. 204-217. 2013.

11. Faiz Uddin Ahmed Shaikh, "Mechanical and durability properties of fly ash geopolymer concrete containing recycled coarse aggregate", International Journal of Sustainable Built Environment, vol. 05, pp. 277-287, 2016

12. Corinaldesi, V., Moriconi, G., "Influence of mineral additions on the performance of $100 \%$ recycled aggregate concrete." Constr. Build. Mater. Vol 23 (8), pp. 2869-2876, 2009

\section{AUTHORS PROFILE}

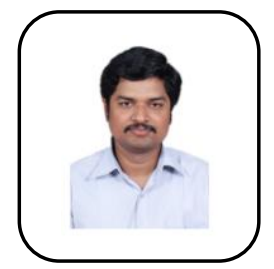

R.Premkumar had completed B.E degree in Civil Engineering and M.E degree in Structural Engineering from Anna University, Chennai, Tamil Nadu in 2008 and 2012 respectively. He is currently working as Assistant Professor in the department of Civil Engineering at Kalasalingam Academy of Research and Education. He has 2 year of industrial experience and 7 years experience in academics and consultancy. His current research interests are Geopolymer Concrete and Earthquake resistance structures.

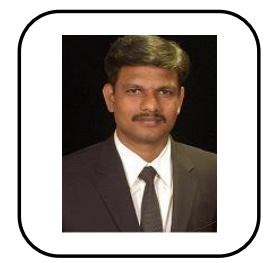

Ramesh Babu Chokkalingam completed his Ph.D. from IIT Chennai. He has more than ten years of experience in teaching and research. His areas of research includes pervious concrete, geopolymer concrete, and high volume flyash concrete.

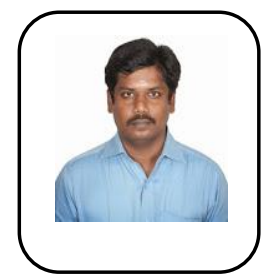

Dr M.Shanmugasundaram: He had completed his B.E degree in Civil Engineering from RCET Madurai, M.E in Structural Engineering, TCE Madurai. He completed his Ph.D in 2014 under the esteemed guidance of Dr. K.Sudalaimani, Professor, TCE, Madurai. He has 30+ international research publications to his credits. He had filed three patents. He has 3 years of industrial experience and 10 years of teaching experience. His recent research interests include, sustainable materials and polymer concrete.

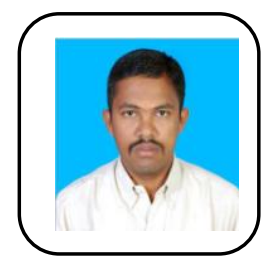

Er.S.Rajesh Completed B.E (Civil) degree from GCE, Tirunelveli in 2009 and M.E (Environmental) degree from ACCET,Karakudi in 2013. He is working as Asst professor in KARE, Krishnankoil and Research scholar in KARE.His research area is Envionmental Engineerring..He is having 7 years Academic Experience and 10 years Industry consultancy Experience. He is Chartered Engineer \& Valuer in India. He is Professional member of the IOV, IEI and PE. He has published more than 10 SCOPUS indexed Journal and Conference in and around India. 